2015-11

\title{
Family Involvement in PICU Rounds
}

\section{Tume, LN}

http://hdl.handle.net/10026.1/5345

10.1097/pcc.0000000000000487

Pediatric Critical Care Medicine

Ovid Technologies (Wolters Kluwer Health)

All content in PEARL is protected by copyright law. Author manuscripts are made available in accordance with publisher policies. Please cite only the published version using the details provided on the item record or document. In the absence of an open licence (e.g. Creative Commons), permissions for further reuse of content should be sought from the publisher or author. 
Tume LN, Latour JM: Family involvement in PICU Rounds: Reality or

Rhetoric? Pediatric Critical Care Medicine 2015;16(9):875-876

Family involvement in PICU Rounds: Reality or Rhetoric?

Lyvonne N. Tume, RN, $\mathrm{PhD}^{1,2}$ and Jos M. Latour, RN, $\mathrm{PhD}^{3,4}$

${ }^{1}$ PICU and Children's Nursing Research Unit, Alder Hey Children's NHS,

Liverpool, United Kingdom

Email: Lyvonne.tume@alderhey/nhs.uk

${ }^{2}$ University of Central Lancashire, School of Health, Preston, United Kingdom.

Email: Intume@uclan.ac.uk

${ }^{3}$ School of Nursing and Midwifery, Faculty of Health and Human Sciences,

Plymouth University, Plymouth, United Kingdom

Email: jos.latour@plymouth.ac.uk

${ }^{4}$ School of Nursing, Midwifery and Paramedicine, Faculty of Health Science,

Curtin University, Perth, WA, Australia

Email: jos.latour@curtin.edu.au

Key-words: Family-centered care; critically ill; child; medical rounds; parent. 
In pediatrics, the family are the centre of the child's life, and crucial to their psychosocial wellbeing and their recovery from illness. Despite the impetus to improve family centered care in pediatric and neonatal intensive care units, practices are not consistent worldwide. In most North American, Antipodean and Northern European PICUs family visitation is not restricted. However, in some countries restrictions still apply to family access, preventing the delivery of family centered care $(1,2)$. Even if families are present in the PICU, their involvement in medical rounds is often restricted or not encouraged. Yet, between $85-100 \%$ of family members in intensive care settings would choose to be present for rounds, if given the choice (1). More specifically, a recent study in PICU found family members believed that their presence during rounds would improve the care of their child; $100 \%$ of parents who were present during a round and $87 \%$ of parents who were absent during a round (3).

There is increasing evidence that family-centered rounds (FCR) increases families' feelings of inclusion and respect, satisfaction with care and promotes a better understanding of their child's care, without significantly prolonging round duration or impairing teaching opportunities (4-6). However, healthcare providers continue to have mixed views about parental participation.

Concerns are expressed by healthcare staff about patient confidentiality, mostly in non-single patient room accommodation, increasing the duration of rounds and limiting teaching and patient discussions $(1,7,8)$. However, the concerns staff express about confidentiality, are not shared by parents $(7,9$, 10). In fact, one study found parents felt confidentiality and intimacy were 
respected better during the bedside rounds, compared to the conference room (5). In addition, we know language barriers impact negatively on healthcare (11), and parents who do not speak the local language inevitably receive suboptimal information and feel least included (12). In an era of global movement and immigration, this remains unacceptable.

In this issue of Pediatric Critical care Medicine, Levin et al (13) reports the results of their study of family participation in PICU ward rounds in a large North American PICU. Their objective was to identify areas for improvement from both parental and healthcare professional perspectives. They used both direct observations of rounds and surveys of staff and English-speaking families. The ethnic profile of their family sample was diverse: $43 \%$ African American, 29\% Caucasian, 22\% Hispanic and 5\% other, and of these, $9 \%$ of these were not English speaking and thus could not participate in the survey. Indeed the non-English speaking families they observed were less likely to be present for the ward round. Not including these families, is a serious flaw in this study, but one they acknowledge.

In this prospective, mixed methods, cross sectional study, they observed 232 family-centered rounds, involving 176 children, over a 10 week period and parents, nurses and physicians were asked to complete a survey after the round. They found that FCR did increase round duration (average of 10.5 minutes per child compared to 8.9 minutes without parental presence); even though the average families talk time during the round was only 25 seconds. It is surprising that round duration was increased given the very short talk time 
of parents, which the authors suggest relates to changes in healthcare providers behaviour. It may also be due to healthcare providers and parents having differing priorities or competing demands. In rounds without parents, healthcare providers do not have to explain terms and some assumptions can be made about common understandings. Increased round duration may also be due to social exchanges with families; however, $50 \%$ of parents in this study felt there was insufficient courteousness shown to them, suggesting this was not the case.

Across the three surveys (nurses, physicians and parents) in the study of Levin and colleagues (13), there was a predominantly positive response about the effects of FCR. However, the PICU fellows did not agree that parents contributed useful information during the round and both physicians and nurses' believed that parental presence hindered patient discussions. A poor nurse response rate of $25 \%$ in this study, limits the ability to draw strong conclusions about the nurses' views, which is a limitation. This unit had practiced this process of FCR for seven years, which may also have impacted upon staff's views, compared to units where involving parents in rounds is new.

Of the 232 FCR observations, there was a parent present at only $52 \%$ of these rounds. In the $48 \%$ of FCR where a parent was not present, $28 \%$ were non-English speaking. A further limitation is that only 12 surveys were completed by parents who chose not to attend the FCR, thus it is not possible to generate reasons for this from these small numbers. Unsurprisingly, 
parent's reasons for FCR attendance were to be informed, to participate in their child's care, and as part of their parental role. However, of note, one third of families did not understand statements made within the round or providers roles. Despite collecting data on parental education level, this variable did not appear to be related to round understanding or provider roles. Interestingly, feedback from the 54 parents about FCR improvements suggested healthcare team needed to be more considerate and courteous.

Opening up clinical rounds for parents and inviting them to stay during the clinical presentation and discussion of health professionals is a sensitive issue. It is not something that can be organised overnight but rather carefully designed providing parents with understandable information how to participate in the care of their critically ill child. At the same time, there is mounting evidence to make clinicians rethink the way medical rounds are conducted. Established and experienced PICU nurses and physicians may need to reconsider their views and behaviors towards families in the PICU. To change to a system where parents are welcomed and empowered to share their expertise, even during a medical and/or a nursing round can be challenging but rewarding. Relatively few, but increasing numbers of studies are available on parental presence during round practices. We hope that the PICU community will continue working on developing and testing effective interventions to improve family-centered care practices. Indeed, a number of nurse experts have classified this area among one of the top research priorities within $\mathrm{PICU}(14,15)$. 
Levin and colleagues (13) remind us about the complexity of empowering parents to join medical and nursing rounds. But the primary change remains with us, as healthcare professionals, to become open-minded and create an empathetic environment for parents, even during rounds. After all, family centered care should not just be rhetoric, but rather deliver the reality of today's families' expectations.

\section{References:}

1. Davidson J: Family presence on Rounds in Neonatal, Pediatric, and Adult Intensive Care Units. Ann Am Thorac Soc 2013; 10: 152-156

2. Griesen G, Mirante N, Haumont D, et al: Parents, siblings and grandparents in the neonatal intensive care unit a survey of policies in eight European countries. Acta Paediatr 2009; 98:1744-1750

3. Drago MJ, Aronson PL, Madrigal V, et al: Are family characteristics associated with attendance at family centered rounds in the PICU? Pediatr Crit Care Med 2013; 14:e93-e97

4. Cypress BS: Family Presence on Rounds: a systematic review of literature. Dimens Crit Care Nurs 2012; 31:53-64

5. Landry MA, Lafrenaye S, Roy MC, et al: A randomized, controlled trial of bedside versus conference-room case presentation in a pediatric intensive care unit. Pediatrics 2007; 120:275-80

6. Phipps LM, Bartke CN, Spear DA, et al: Assessment of parental presence during bedside pediatric intensive care unit rounds: effect on duration, teaching, and privacy. Pediatr Crit Care Med 2007; 8:220-224 
7. Aronson P, Yau J, Helfaer M, et al: Impact of Family Presence During Pediatric Intensive care Unit Rounds on the Family and medical Team. Pediatrics 2009: 124:1119-1125

8. McPherson $\mathrm{G}$, Jefferson R, Kissoon N, et al: Toward the inclusion of parents on pediatric critical care unit rounds. Pediatr Crit Care Med 2011: 12:e255-e261

9. Abdel-Latif ME, Boswell D, Broom D, et al: Parental presence on neonatal intensive care unit clinical bedside rounds: randomised trial and focus group discussion. Arch Dis Child Fetal Neonatal Ed 2015; 100:F203-F209

10. Latour JM, Albarran JW: Privacy, dignity and confidentiality: a time to reflect on practice. Nurs Crit Care 2012; 17:109-111

11. Guerrero AD, Chen J, Inkelas M, et al: Racial and Ethnic disparities in Pediatric Experiences of family-centered care. Med Care 2010; 48:388393

12. Seltz L, Zimmer L, Ochoa-Nunez L, et al: Latino families' experiences with family-centered rounds at an academic children's hospital. Acad Pediatr 2011; 11:432-438

13. Levin A, Fisher K, Cato K, et al: An Evaluation of Family-Centered Rounds in the Pediatric Intensive care Unit: Room for improvement suggested by Families and Parents. Pediatr Crit Care Med 2015: xxxxx

14. Tume $L N$, van den Hoogen A, Wielenga JM, Latour JM: An electronic delphi study to establish pediatric intensive care nursing research priorities in twenty European countries. Pediatr Crit Care Med 2014; 15:e206-e213 
15. Tume LN, Coetzee M, Dryden-Palmer K, et al: Pediatric Critical Care Nursing Research Priorities-Initiating International Dialogue. Pediatr Crit Care Med 2015; Epub ahead of print. DOI: 10.1097/PCC.0000000000000446 